\title{
Caracterização Geofísica da ocorrência de Mármore Dolomítico a partir do Método da Eletrorresistividade
}

\author{
Guilherme Freitas Ilha ${ }^{1}$, Fábio Henrique Rigoti ${ }^{1}$, Marcel Magalhães Sobrinho', Eduardo Almeida Bueno'; Cauê Vivian \\ Hess $^{1}$; José Pedro Rebés Lima; Candido Francisco de Avila Baptista ${ }^{1}$; Raul Oliveira Neto ${ }^{1}$ \\ 1 Universidade Federal do Pampa (UNIPAMPA)
}

\begin{abstract}
Este texto foi preparado para a apresentação no VI Simpósio Brasileiro de Geofísica, Porto Alegre, 14 a 16 de outubro de 2014. Seu conteúdo foi revisado pelo Comitê Técnico do VI SimBGf, mas não necessariamente representa a opinião da SBGf ou de seus associados. E proibida a reprodução total ou parcial deste material para propósitos comerciais sem prévia autorização da SBGf.
\end{abstract}

\section{Resumo}

A pesquisa foi realizada em uma área de mineração de mármore dolomítico, localizada no município de Caçapava do Sul, Rio Grande do Sul. O trabalho aborda uma metodologia de aquisição e processamento de dados de eletrorresistividade, a partir de um perfil A-B, utilizando a técnica de caminhamento elétrico (CE) e arranjo dipolo-dipolo, onde a implantação da linha contou com equipamento topográfico Estação Total, fornecendo precisão centimétrica na determinação planialtimétrica. $O$ algoritmo de inversão dos dados foi usado para encontrar os valores de resistividade real através dos valores de resistividade aparente medidos. A análise desses dados possibilitou reconhecimento de feições estruturais e a confecção de um modelo geoelétrico e geofísicogeológico de subsuperfície, delimitando contatos litológicos através do contraste de resistividade elétrica, juntamente com informações de furos de sondagens locais. Assim possibilitando observar o comportamento do mármore dolomítico em subsuperfície, e o contato com o granito. A partir desta metodologia de trabalho foi possível encontrar um resultado satisfatório no reconhecimento e análise das estruturas e litologias presentes na área de estudo, fazendo um importante papel de difundir a geofísica em mineradoras que desconheciam sua importância e utilidade.

\section{Introdução}

O mármore dolomítico é uma rocha metamórfica proveniente do calcário dolomítico (rocha sedimentar), seu principal componente é o carbonato de cálcio.

A exploração desse mineral é devido as suas varias utilidades, serve como fertilizante na correção da acidez de solos ácidos e também como matéria-prima para a fabricação da cal virgem, cal hidratada e argamassa amplamente usados na construção civil (SAMPAIO; ALMEIDA 2008).

Devido a esses fatores, a prospecção do mármore é altamente importante, e pode ser realizada por meio de métodos diretos e indiretos. Como método indireto, usase a geofísica, através da medida das propriedades físicas do meio, em superfície, que mostra o comportamento dos corpos em subsuperfície. Os métodos elétricos são considerados dos mais versáteis dentro da geofísica aplicada, sendo extensamente aplicados em prospecção mineral, prospecção de águas subterrâneas, estudos de geologia de engenharia e estudos ambientais. Por meio desse método geofísico abordado é possível obter modelos de subsuperfície através da caracterização geoelétrica do mármore, devido ao contraste da propriedade física condutividade/resistividade dos corpos em questão, o que fornecerá uma compreensão detalhada de seu comportamento em sub-superfície. Os resultados obtidos através desses métodos poderão ser usados para um melhor gerenciamento de lavra e no planejamento de novas atividades de exploração mineral.

O levantamento de dados de eletrorresistividade juntamente com informações de furos de sondagens, teve como objetivo observar a resposta deste método em um meio geológico no qual encontram-se duas rochas com propriedades elétricas semelhantes, tornando fundamental para interpretação dos resultados geofísicos o entendimento do processo da intrusão granítica nas rochas calcárias e seu consequente metamorfismo.

\section{Área de estudo}

A área de estudo situa-se no sudeste (SE) do município de Caçapava do Sul, a aproximadamente $15 \mathrm{~km}$ da cidade. (Figura 1)
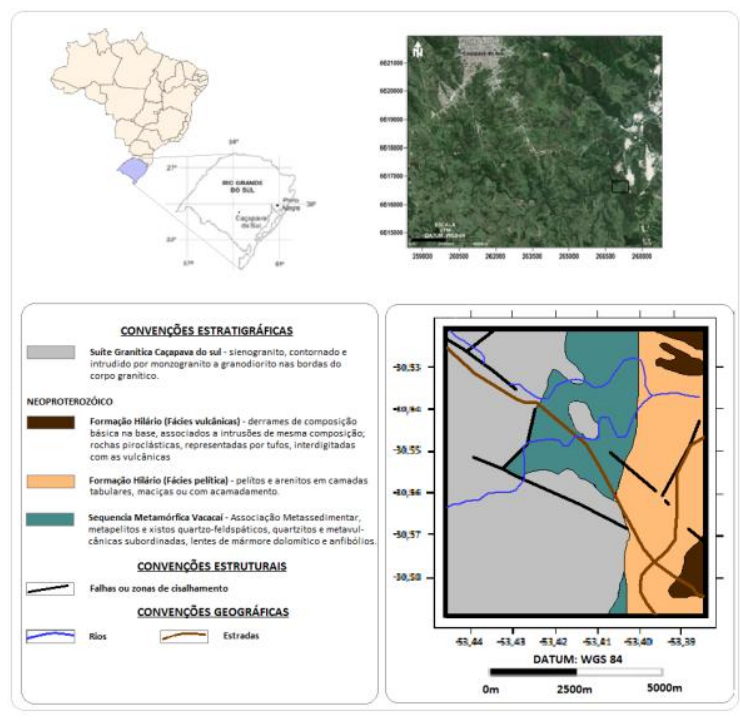

Figura 1: Mapa de localização (faixa superior) e Mapa geológico (faixa inferior) da área de estudo.

O local da pesquisa é delimitado pelas coordenadas: Latitudes - 30॰31'16.7101"S e 30³5'45.7195"S;

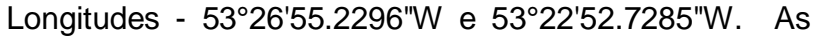
litologias presentes na área de estudo, estão inseridas no domínio ocidental do Escudo-Sul-Rio-Grandense, onde estão representadas pela Sequência Metamórfica 
Vacacaí e pela Suíte Granítica Caçapava do Sul. A geologia presente é predominantemente composta por metapelitos e xistos quartzo-feldspáticos, quartzitos e metavulcânicas da Sequência Metamórfica Vacacaí, do Neoproterozóico ( 950 Ma) e por metagranitóides de composição sieno a monzogranítica da Suíte Granítica Caçapava do sul ( 600 Ma) (CPRM, 2000).

\section{Metodologia geofísica empregada}

Dentre os principais métodos geofísicos encontram-se os que obtêm propriedades elétricas dos solos e rochas, denominados de forma genérica como métodos geoelétricos. No presente estudo, limita-se a discussão ao método geoelétrico galvânico, em que, através de eletrodos aterrados, aplica-se uma corrente elétrica e mede-se uma diferença de potencial. $O$ desenvolvimento principal do método se deve a ampla aplicação da eletrorresistividade dos solos e rochas na exploração mineral. Na mineração, aplicações do método evoluíram para subsidiar a lavra, fornecendo informação sobre a estratigrafia e aspectos hidrogeológicos e estruturais.

A eletrorresistividade, propriedade física doravante simplificada para o termo resistividade, é medida através da criação de um campo elétrico artificial gerado na superfície do terreno. Para tanto, uma corrente elétrica é aplicada no solo por contato galvânico de dois eletrodos denominados $A$ e $B$ e a diferença de potencial elétrico resultante é medida por um par de eletrodos denominados $\mathrm{M}$ e $\mathrm{N}$, nomenclatura amplamente utilizada (e.g. DUARTE, 2007). Sendo, em geral, o conteúdo de água ocupando os poros das rochas e solos o fator mais determinante do valor da resistividade (e.g. ORELLANA, E; 1972; TELFORD, et al. 1976).

A implantação da linha de aquisição em campo, levou em consideração a posição dos furos de sondagens na área, procurando passar o mais próximo possível destes. (Figura 2)

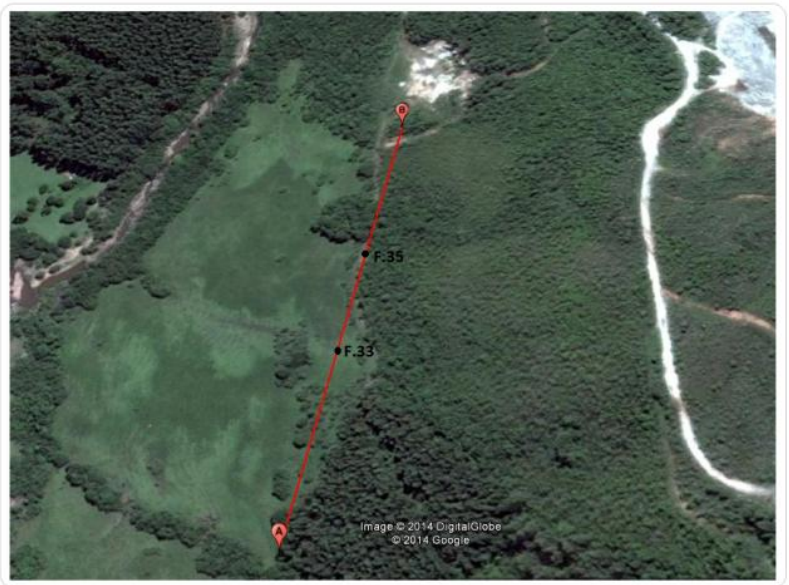

Figura 2: Linha de aquisição dos dados com extensão de $360 m$ (Perfil A a B), juntamente com os furos de sondagens $F .33$ e F.35.

A aquisição de dados de resistividade foi feita com a técnica de caminhamento elétrico (CE) e arranjo dipolodipolo, com espaçamento de 5 metros entre eletrodos nos pares transmissor e receptor. A extensão da linha foi de 360 metros e a profundidade teórica de investigação foi em torno de 67 metros, por estimativas descritas por Edwards (1977), como "median depth of investigation", cálculos contidos no software de processamento utilizado e atualmente os mais aceitos pelo meio técnico.

A implantação da linha de CE contou com equipamento topográfico Estação Total RTS-820 fabricado pela Ruide Intruments, fornecendo precisão centimétrica na determinação planialtimétrica.

A aquisição dos dados de eletrorresistividade foi realizada com o equipamento multieletrodo SYSCAL PRO Switch-72 de 10 canais e 72 eletrodos, fabricado pela IRIS Instruments. Foi utilizado o modo automatic sequence, que muda automaticamente os pares transmissor e receptor na sequência de medidas programadas. A corrente resultante foi em forma de onda quadrada com duração dos pulsos de 2 segundos e mínimo de 4 e máximo de 8 ciclos, aplicando-se tensão de 800 Volts nos eletrodos de corrente.

O processamento dos dados foi realizado com o software RES2Dinv comercializado pela própria IRIS Instruments. A inversão 2D é um processo iterativo que busca uma seção modelo, também chamada seção "real" de resistividade, capaz de gerar uma pseudo-seção de resistividade aparente que reproduz de forma aceitável ou satisfatória a pseudo-seção medida. O erro RMS (Root Mean Square) percentual revela quanto bem a pseudo-seção calculada se ajusta à medida observada.

Para facilitar a interpretação da seção "real" de resistividade, principalmente salientando zonas condutoras, utilizou-se o software Oasis Montaj-Geosoft que possibilitou uma visualização em cores mais adequada, historicamente utilizada na mineração, com tons branco/azulados indicando as mais altas resistividades e roxo/avermelhadas, as mais baixas.

\section{Resultados}

Através do software RES2DINV, antes de apresentar os resultados das inversões, são mostradas as pseudoseções de resistividade aparente observada e calculada (Figura 3). Considerando um semi-espaço homogêneo com resistividade constante e igual à média dos logaritmos dos valores das resistividades aparentes da pseudo-seção. A densidade de amostragem está representada como pontos brancos nas seções. A similaridade da pseudo-seção calculada com a observada está representada pelo erro RMS de $9.6 \%$, resultado considerado bom devido ao grande contraste de resistividade elétrica de sub-superfície, o que dificulta matematicamente a aproximação do modelo. Nesta etapa do processamento, ainda não é inserida a topografia, sendo esta incluída apenas após o processo de inversão.

A figura 4 mostra o modelo de inversão com realce dos condutores nas cores roxo/avermelhadas, dos mais resistivos nas branco/azuladas e seus intermediários. Pode-se observar que a qualidade e resolução dos dados, permitiram a identificação dos níveis condutores associados ao manto de alteração e rocha com alto grau 
de fraturamento e alteração, dos níveis intermediários caracterizando a rocha com menor grau de alteração e fraturamento e dos níveis de alta resistividade condizente à de rocha sã.

Analisando as descrições dos furos das sondagens F33 (Tabela 1) e F35 (Tabela 2), plotadas na seção "real" de resistividade (Figura 5), nota-se que os núcleos de alta resistividade estão relacionados ao minério de mármore. Entretanto, há uma significativa camada de mármore bastante alterado e saturado acima do núcleo resistivo. A resistividade dessa fácie não difere do granito fraturado/alterado encontrado na zona de fraturas abaixo do furo 35. Sendo assim, para a determinação de um modelo litológico a partir dos dados de eletrorresistividade, é fundamental a análise da geologia estrutural local e regional.

Tabela 1: Informações do furo de sondagem 33 (F.33).

\begin{tabular}{|c|c|c|}
\hline $\begin{array}{c}\text { Espessura } \\
(\mathbf{m})\end{array}$ & $\begin{array}{c}\text { Profundidade } \\
(\mathbf{m})\end{array}$ & $\begin{array}{c}\text { Descrição dos } \\
\text { testemunhos de } \\
\text { sondagem }\end{array}$ \\
\hline 3.1 & 0 a -3.1 & $\begin{array}{c}\text { Material } \\
\text { inconsolidado }\end{array}$ \\
\hline 8.3 & -3.1 a -11.40 & $\begin{array}{c}\text { Mármore bastante } \\
\text { fraturado/alterado }\end{array}$ \\
\hline 30.72 & -11.40 a -42.12 & Mármore são \\
\hline 10.68 & -42.12 a -52.80 & Granito são \\
\hline
\end{tabular}

Tabela 2: Informações do furo de sondagem 35 (F.35).

\begin{tabular}{|c|c|c|}
\hline $\begin{array}{c}\text { Espessura } \\
(\mathrm{m})\end{array}$ & $\begin{array}{c}\text { Profundidade } \\
(\mathrm{m})\end{array}$ & $\begin{array}{c}\text { Descrição dos } \\
\text { testemunhos de } \\
\text { sondagem }\end{array}$ \\
\hline 7.0 & 0 a -7.0 & $\begin{array}{c}\text { Material } \\
\text { inconsolidado }\end{array}$ \\
\hline 30 & -7.0 a -37.0 & $\begin{array}{c}\text { Granito bastante } \\
\text { fraturado /alterado }\end{array}$ \\
\hline
\end{tabular}

O furo 33 não descreve um nível intermediário, e de fato, pelos dados geofísicos a mudança de porosidade e saturação é bastante abrupta do manto de alteração para a rocha sã. $\mathrm{O}$ furo atingiu profundidade de 52,80 metros, sendo que a partir de 42,12 , o material foi caracterizado como granito são. Contudo, o método não mostrou sensibilidade vertical para diferenciar o mármore são do granito são a essa profundidade. A perda da resolução com o aumento da profundidade investigada é uma limitação dos métodos geofísicos em geral. Embora os dois litotipos se caracterizem por altas resistividades em seu estado são, possivelmente, quando mais próximo da superfície, o contato possa ser definido.

O furo 35 foi locado acima de uma zona de fraturas e atingiu profundidade de $37 \mathrm{~m}$. Esse furo foi caracterizado apenas por solo e litologia granítica, sugerindo que a intrusão granítica no calcário gerou e ocupou as zonas de fraturas, rompendo as zonas calcárias de maior fragilidade e metamorfizando-a em mármore.

\section{Conclusões}

Os dados de eletrorresistividade obtidos por contato galvânico com a técnica de caminhamento elétrico e arranjo dipolo-dipolo se mostrou bastante eficiente na identificação do comportamento do mármore em subsuperfície e localização das zonas de fraturas para a caracterização da área de estudo. $O$ posicionamento de fraturas pode ser correlacionado com 0 de intrusões graníticas. Altas e baixas resistividades por si só não revela a litologia, uma vez que, o presente estudo mostrou os dois extremos de resistividade tanto para o mármore quanto para o granito. Entretanto, resultados geoelétricos aliados ao conhecimento e análise de geologia estrutural, permitem a redução da ambiguidade e o desenvolvimento de modelos litológicos. A natureza tridimensional dos corpos de mármore nesse contexto geológico, sugere que a aquisição e inversão 3D é a mais adequada para evitar falseamento da distribuição da propriedade física em subsuperfície. Por fim, esta pesquisa mostrou um importante papel de difundir a geofísica em mineradoras que não tinham conhecimento de sua importância e utilidade, podendo servir como apoio às soluções das variáveis da frente de lavra, e ainda fornecer informações para locação dos furos de sondagens, minimizando o número de sondagens realizadas em lugares inadequados.

\section{Agradecimentos}

Nossos formais agradecimentos à Universidade Federal do Pampa, por tornar possível a elaboração desse trabalho disponibilizando os instrumentos necessários. $\mathrm{E}$ aos nossos colegas e professores que gentilmente nos auxiliaram na aquisição, processamento e interpretação dos dados.

\section{Referências}

CPRM - Serviço Geológico do Brasil. Geologia e Metalogênese. FOLHA SH. 22-Y-A, Estado do Rio Grande do Sul, Escala 1:250.000. Brasília: 2000. CDROM

DUARTE, O. O. Dicionário enciclopédico inglêsportuguês: Geofísica e Geologia. $3^{\mathrm{a}}$ edição. Brasil: SBGF, 2007.

EDWARDS, L. S. A modified pseudosection for resistivity and IP. Geophysics, Vol. 42, NO. 5. United States of America:SEG, 1977.

ORELLANA E. Prospeccion geoelectrica: en corriente continua. $2^{a}$ edição. Espanha: Paraninfo, 1972.

TELFORD, W. M; GELDART, L. P; SHERIFF, R. E; KEYS, D. A. Applied geophysics. $1^{\text {a }}$ edição. United States of America: Press Syndicate of the University of Cambridge, 1976.

OASIS MONTAJ, V 6.4.2 (HJ) - Standart Edition.

Copyright 2007, Geosoft Inc. 
ALMEIDA, F.F.M. et al. Brazilian structural provinces; na introduction. Earth Science Reviews, Amsterdam, 17(1/2): 1-29, Apr. 1981
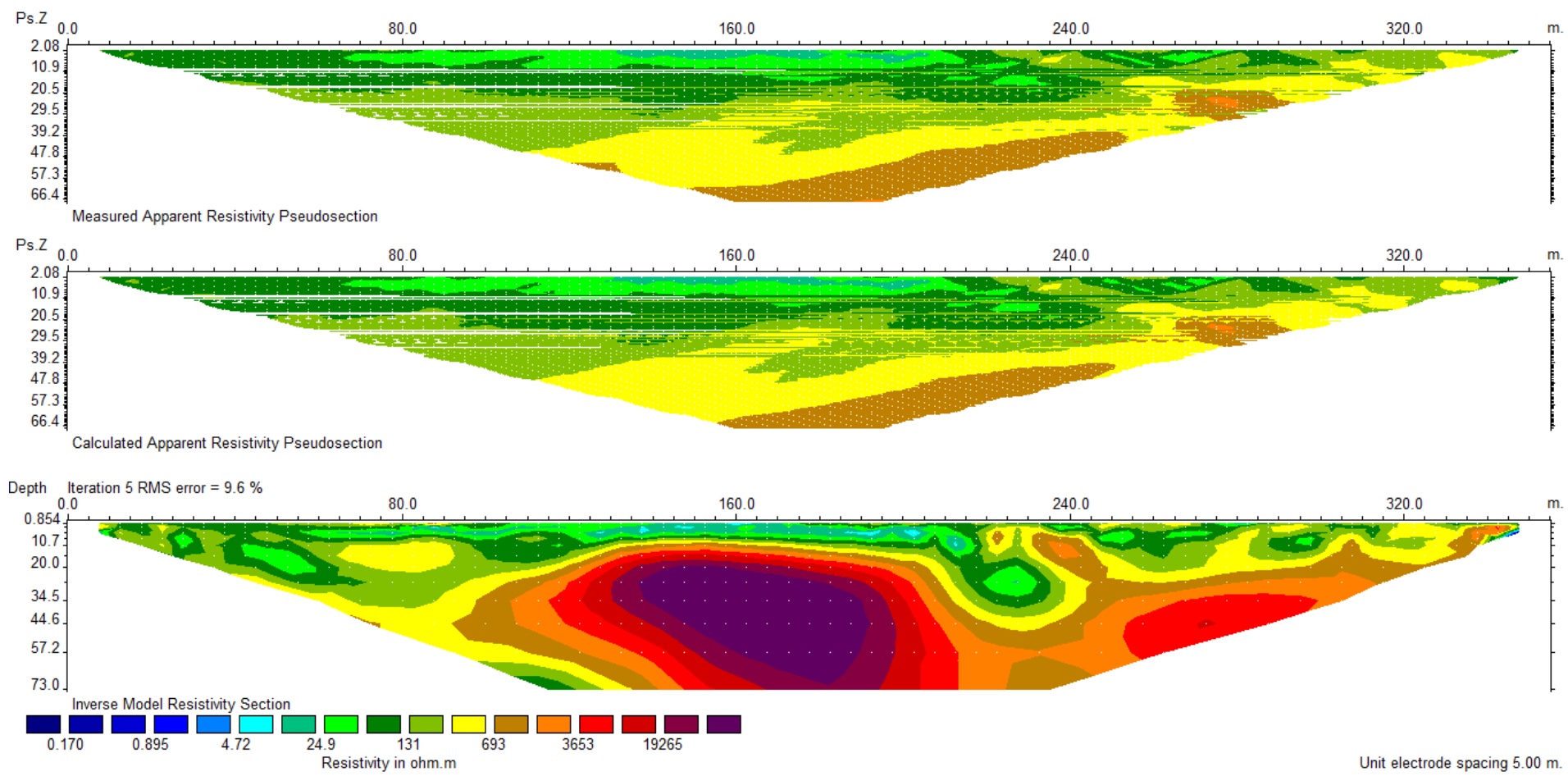

Figura 3: Resultados da inversão $2 D$ de resistividade elétrica. Levantamento em linha retilínea na superfície, utilizando a técnica de caminhamento elétrico com arranjo dipolo-dipolo, espaçamento de 5 metros entre eletrodos nos pares transmissor e receptor e leituras do $1^{\circ}$ ao $16^{\circ}$ nivel (profundidade) de investigação. No topo a pseudo-seção observada (medida) e no meio a calculada a partir da seção modelo (seção "real”) de resistividade elétrica da base do quadro. Os pontos brancos nas seções representam pontos amostrados. $O$ satisfatório erro RMS pode ser observado no canto superior esquerdo da seção "real". 


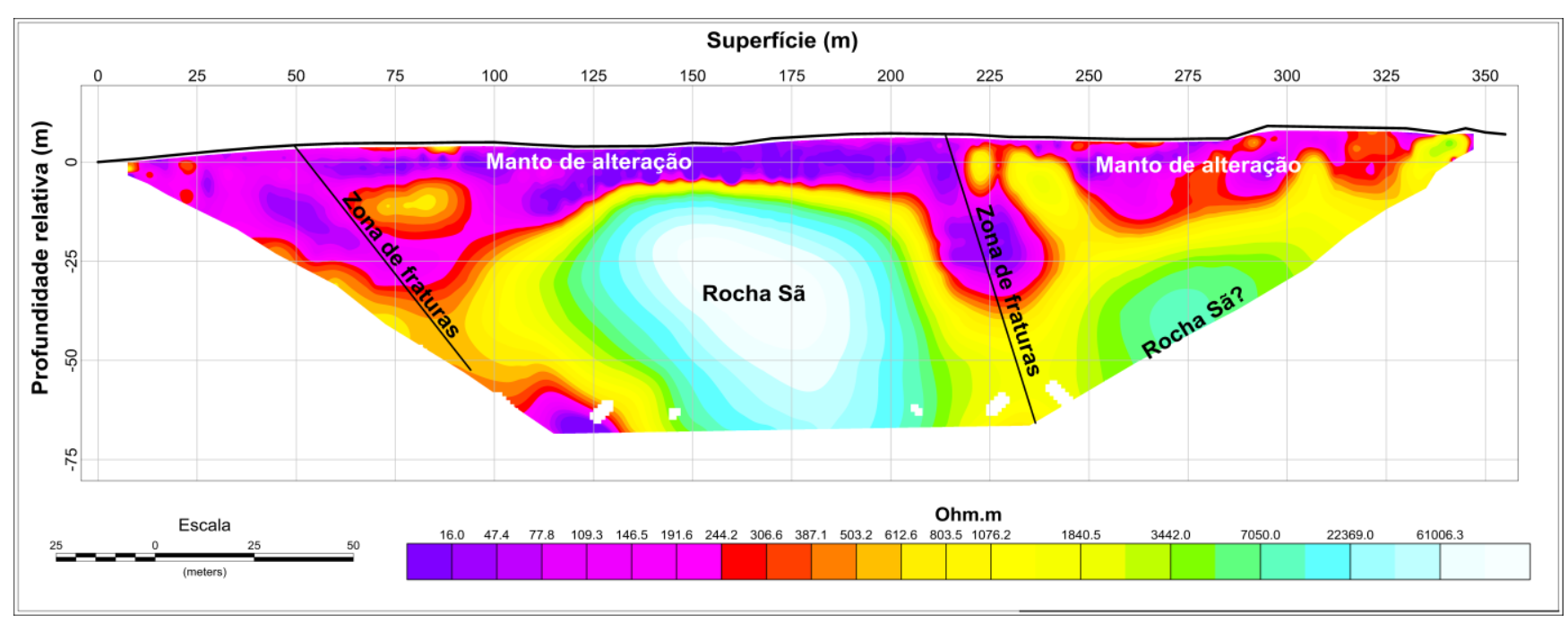

Figura 4: Interpretação da seção "real" de resistividade elétrica, com a variação topográfica. Pode-se identificar zonas condutivas, que são, manto de alteração e zonas de fraturas, e estão indicados por baixa resistividade (tons vermelho/roxo); o amarelo está relacionado à uma zona de transição da cobertura saturada ou manto de alteração com a rocha sã, com valores de resistividade em torno de 1000 ohm.m, trata-se de baixo grau de fraturamento/alteração; no centro da seção é possível identificar altos valores de resistividade, que estão denominados a rocha sã, podendo ser um corpo de mármore dolomítico.

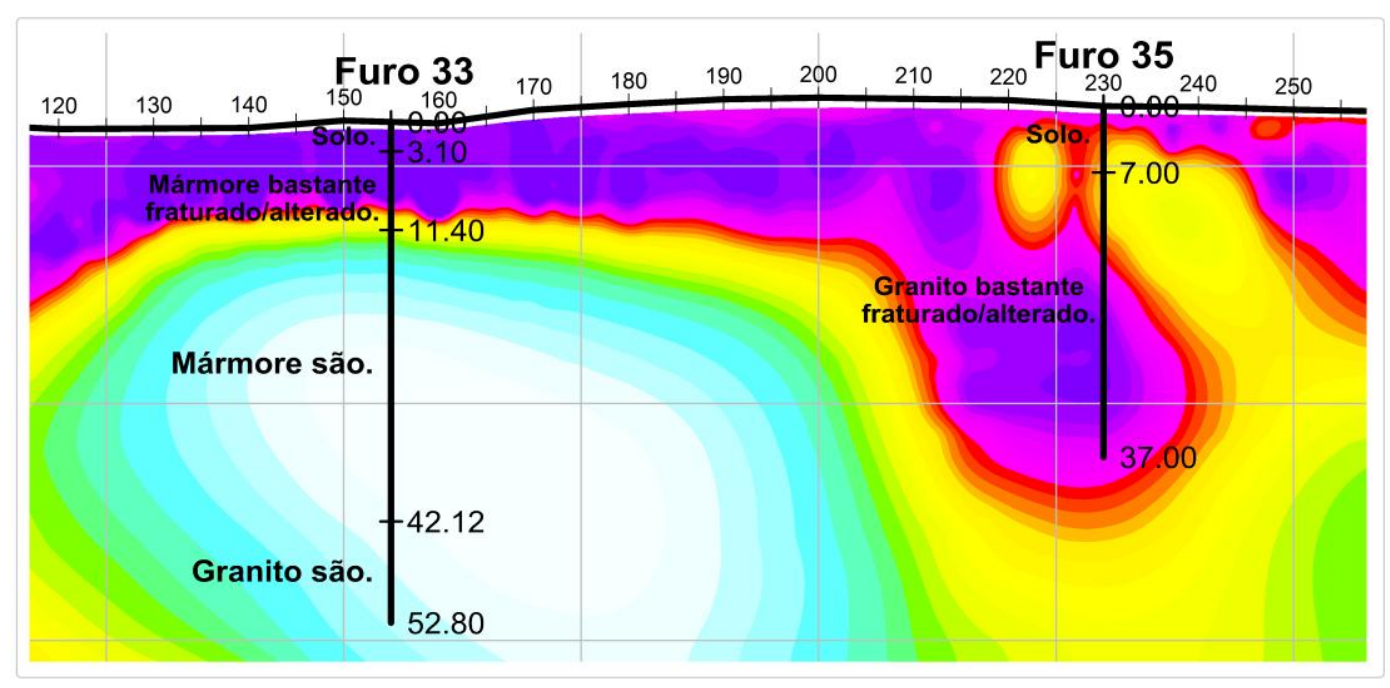

Figura 5: Recorte da seção de resistividade, com a localização e descrição dos furos de sondagens 33 e 35. Devido as informações do furo de sondagem 33, foi possível identificar que o corpo anômalo no centro da seção, está relacionado ao mármore dolomítico, mas que a partir da profundidade 42.12, onde começou o granito mais são, ou seja, sem alteração, o método não identificou esse contato. No resultado do furo 35, observa-se que este está localizado em uma zona de fratura com resistividades baixas, devido ao granito possuir um grau de fraturamento muito elevado, e assim possuindo intensa percolação de água. 